\title{
Structural Design of Philippine Arena
}

\author{
Jong Soo Kim, Hyun Hee Ryu, Duck-Won Cho and Keum Jung Song \\ CS Structural Engineering, Seongnam, Gyeonggi 462-807, Korea
}

\begin{abstract}
The Philippine Arena Project is a large domed roof structure. The arena volume is significant, with $227 \mathrm{~m} \times 179 \mathrm{~m}$ ellipse shaped space standing, which is the largest non-column arena in the world. Reinforced concrete is used for the bowl structure and main seismic resisting system is considered as dual system. For the structure above Level 04, steel rakers and columns are applied. To identify seismic resisting performance of steel structure, push over analysis had been carried out. Pre-cast concrete plank is planned for arena seating to meet constructing ability. The roof structure is grid type space frame. Tension trusses are located under the space frame for overall stability of roof structure. Wind tunnel test had been conducted to evaluate accurate wind pressure for both structure and cladding design. LRB (lead rubber bearing) is located under the roof structure to reduce seismic force delivered from sub-structure.
\end{abstract}

Key words: Spatial structure, space frame, arena, dome, isolator, lead rubber bearing.

\section{Introduction}

Philippine Arena (Fig. 1) site is located in Barangay Duhat, Bocaue, Bulacan, which is north-west side of Manila, capital of Philippines. It is a 50,000 seated domed roof structure which is the largest non-column area in the world, measured to be around $227 \mathrm{~m} \times$ $179 \mathrm{~m}$. It opened in July 2014 to hold 100-year anniversary ceremony of INC (Iglesia ni Cristo). After the ceremony, it has been used as a concert hall and sports activities, also. As the construction period was limited, Philippine Arena was constructed as fast track.

There were preliminary concept design group with local architects and engineers. After that, Hanwha E\&C (Hanwha Engineering and Construction Corp.) won a contract to cover design and build. CSSE (CS Structural Engineering) Inc. and HA (Haeahn Architecture) joined with Hanwha E\&C as a design group to provide SD (schematic design), DD (design development) and $\mathrm{CD}$ (construction documents).

Philippine Arena can be divided into four major parts: roof, upper bowl (above of Level 04), lower bowl

Corresponding author: Jong Soo Kim, CEO, research field: structure engineering. and service core with loading dock. Roof and upper bowl are steel system and lower bowl and service core are reinforced concrete system (Fig. 2).

\section{Design of Lower Bowl}

As long as Philippine is in strong ground motion area, structural members were mainly governed by seismic force. For this reason, it was very important to select proper seismic force resisting system from the beginning of the structural design $[1,2]$. From the analysis, it was found that frame was resisting about $43 \%$ of seismic load and shear wall was resisting $57 \%$ (Fig. 3). From this result, dual system had been selected for lower bowl. This means at least $25 \%$ of lateral load should be resisted by frames without shear walls. Hence, adequate reinforcing on column and girder was applied for ductile behavior of the frame.

For seating plank, PC (pre-cast concrete) was applied for constructability and economic quantity of material. Also, PC stand was planned for diaphragm action of bowl structure. Axial displacement of PC stand, due to gravity and temperature load, was checked and short slotted hole was applied on connection detail with rakers. With the slotted hole, 


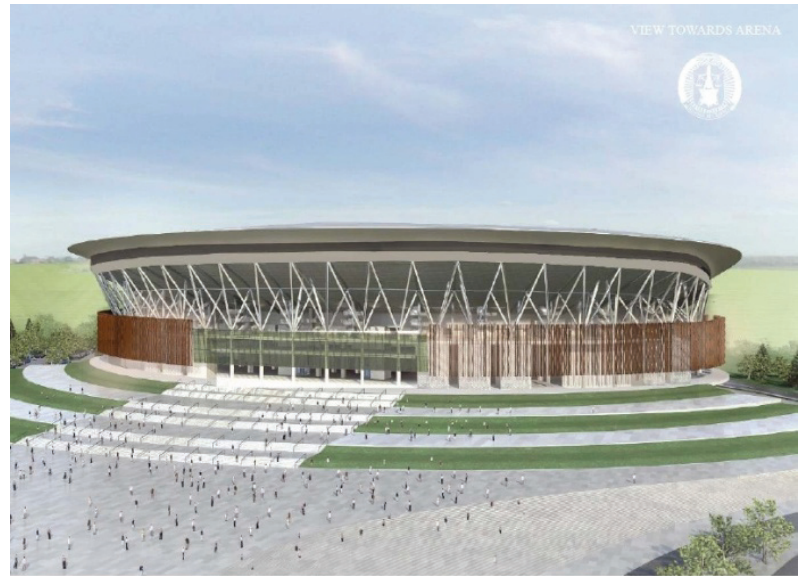

Fig. 1 Philippine Arena.

displacement only for the amount of the gravity and temperature load can be acceptable. And if there is more displacement than the length of slotted hole, due to lateral load, stand elements start to act as a diaphragm. To find out in-plane force (diaphragm force) of PC stand, it was considered as plate element in FEM (finite element method) analysis.

\section{Design of Upper Bowl}

Upper bowl [3, 4] is supported by 4-way inclined columns (Fig. 4). From the seismic resisting system categories on design code, SCBF (special concentrically braced frame) and SMRF (special moment resisting frame) could be applied for upper bowl system. For SCBF, it was required that plastic hinges shall be originated on braces first, not columns. This means columns of SCBF shall remain in elastic range to resist gravity load safely, even under severe earthquake. From the analysis modelling, inclined columns behaved like braces (axial force governed) but they should resist gravity load, too, as if they were columns. So applying SCBF for upper bowl was inadequate. Otherwise, SMRF requires the frame action and plastic hinges from lateral loads shall be originated on girders. However, the upper bowl structure acted like braced frame as mentioned above. Therefore, applying SMRF was inadequate either.

To conclude, it was difficult to apply seismic resisting system categorized in design code. However, from the shape of structure itself, it is expected that it has enough stiffness to perform elastic behavior on seismic force. To confirm safety of the structure, push over analysis was performed which can estimate capacity of structure resisting seismic load. As a result, it was clarified that columns, rakers and girders of upper bowl remain in elastic range in case of earthquake.

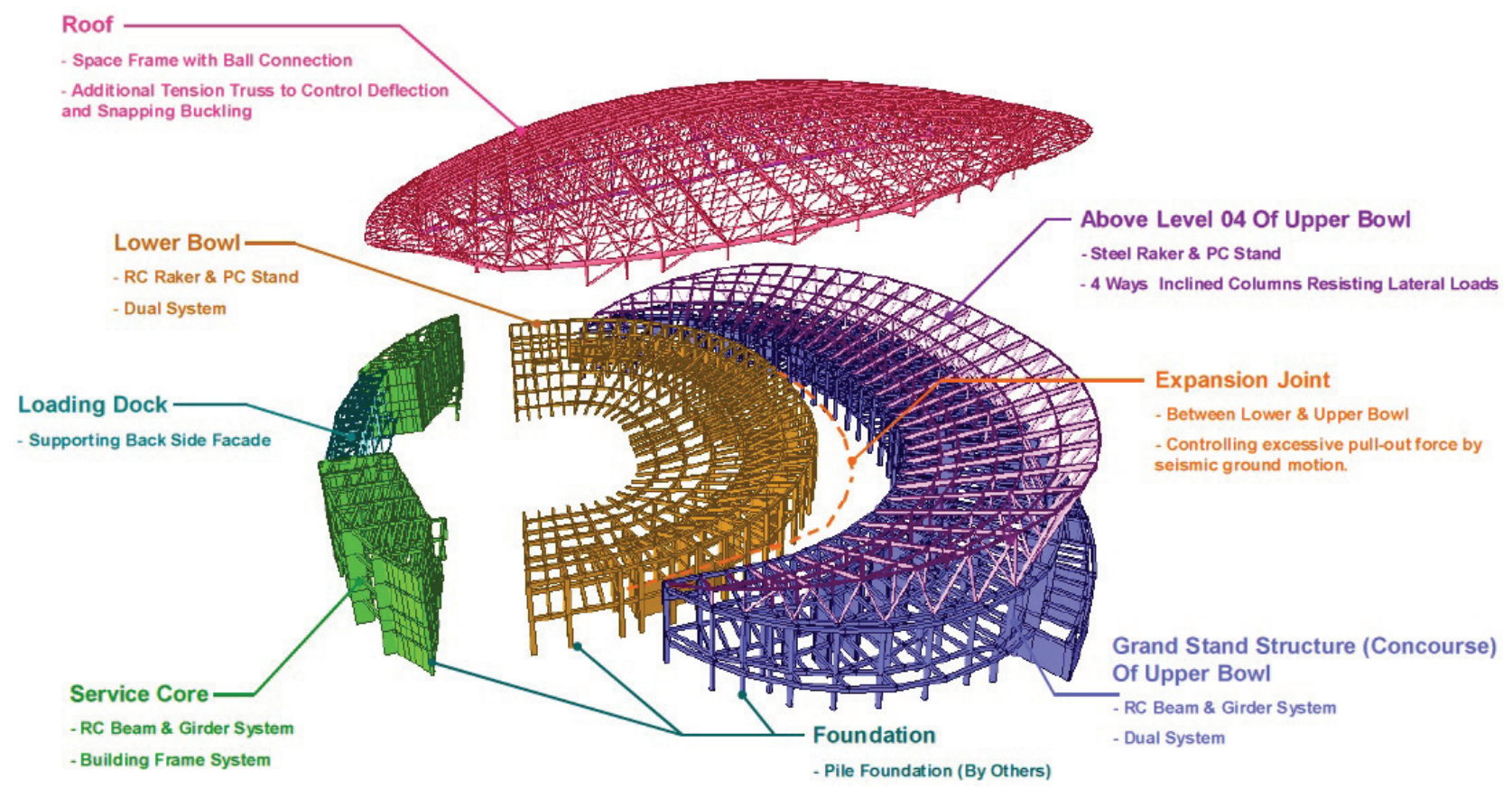

Fig. 2 Structural summary of Philippine Arena. 


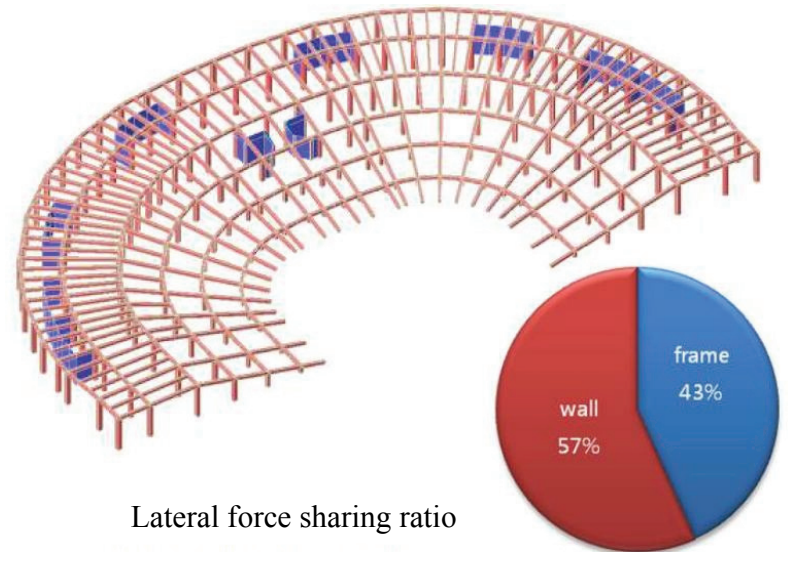

Fig. 3 Lateral force sharing ratio of lower bowl.

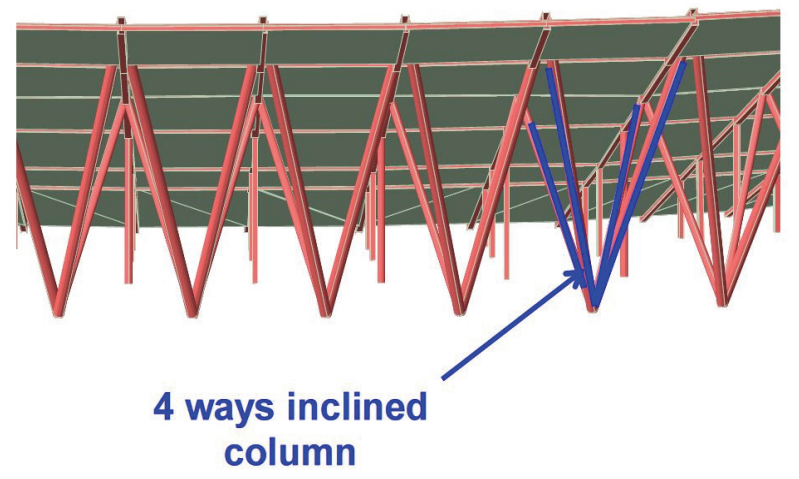

Fig. 4 Columns of upper bowl.

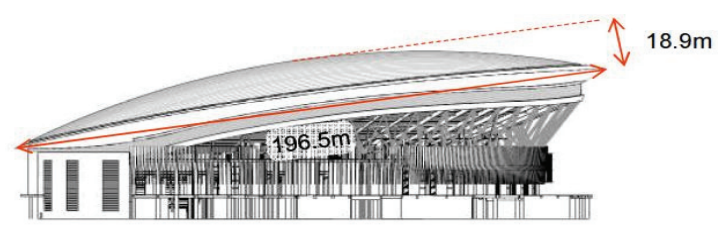

Major-Axis : $18.9 / 196.5=0.096$

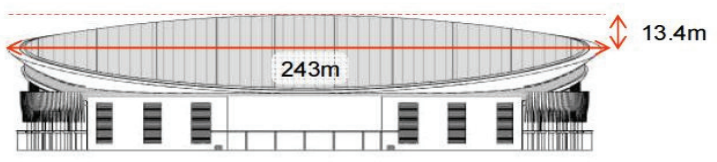

Minor-Axis : $13.4 / 243.0=0.055$

Fig. 5 Overall geometry of roof structure.
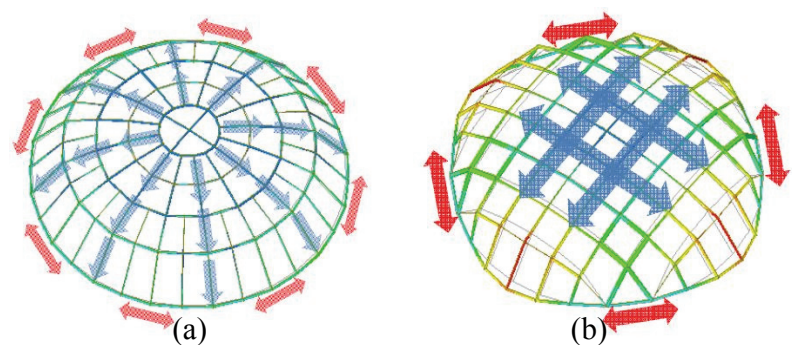

Fig. 6 Applicable space frame: (a) radial; (b) grid.
Structural elements were designed with amplified seismic force by over strength factor $(\Omega=2.8)$ to be safe at the force level with elastic response.

\section{Roof System}

\subsection{Introduction}

The roof size of Philippine Arena [5-7] is approximately $227 \mathrm{~m} \times 179 \mathrm{~m}$. Roof shape was drawn from the torus shape and span-rise ratios were 0.096 for major axis and 0.055 for minor axis (Fig. 5). Because the roof does not have enough rise height to expect arch action, deriving reasonable system for roof was quite challenging issue for structural engineer.

\subsection{Roof Structural System}

Spatial structures are divided into two groups: rigid structure and flexible structure. The flexible structure is lightweight which can control long span economically, but it has limitation in selection of finishing material selection. The rigid structure can control long span as well, but limited to satisfy shape of structure. The roof structure of Philippine Arena had many restrictions such as metal cladding and low span-rise ratio. Thus, Space frame was selected to be the most satisfactory structure to perform $180 \mathrm{~m}$ long span.

Applicable space frame types were divided into two groups (Fig. 6): Radial type could distribute external force uniformly to the outer ring, and it had better shape resistance performance with multi-layered rings; Grid type had lower efficiency of outer ring because external load was concentrated on partial areas only. However, Philippine Arena has ellipse shaped roof, radial type space fame could arise many problems such as increasing number of element and size of connection, and it required various shapes of secondary elements for cladding and internal ceilings. Also, for roof structures with low span-rise ratio are tend to rely on vector action, so forming the radial type did not have great effectiveness.

Therefore, the space frame was selected to be 
formed as a grid type because it had great advantages from becoming structural modulation.

To form space frame such like, horizontal thrust shall be restrained along the roof edge to keep arch action for dome structures. Thus, outer tension ring is very important.

The tension ring (Fig. 7) is effective when the shape is close to perfect circle. Philippine Arena roof is shaped of ellipticity and the tension ring can not effectively restrain the displacement of edge of roof. The curvature of $\mathrm{y}$-direction is larger than $\mathrm{x}$-direction, and the displacement of $\mathrm{y}$-direction is larger than $\mathrm{x}$-direction. Thus, it is required to install additional sub-tensioning member (Fig. 8) that helps restraining action in y-direction.

The performance of shape resistance is low from the low span-rise ratio of roof structure. The tension ring with tension trusses can share its stress and stiffness of the roof is increasing. As a result, the deflection decreased effectively.

It is better by increasing structure's stiffness than only deploying tension ring of restrained condition. It is optimum to control deflection when the tension truss locates close to center, but to be well balanced with architecture design, the tension trusses are planned to be located at one-third of span, two places. Installing tension truss can be also effective for resisting snapping buckling.

\subsubsection{Gravity Load Resistance System}

Gravity load resistance system (Fig. 9) is composed with space frame forming the shape. Tension ring and tension trusses secure the stiffness and columns. The space frame restrained by the outer tension ring can distribute gravity load uniformly through the arch action.

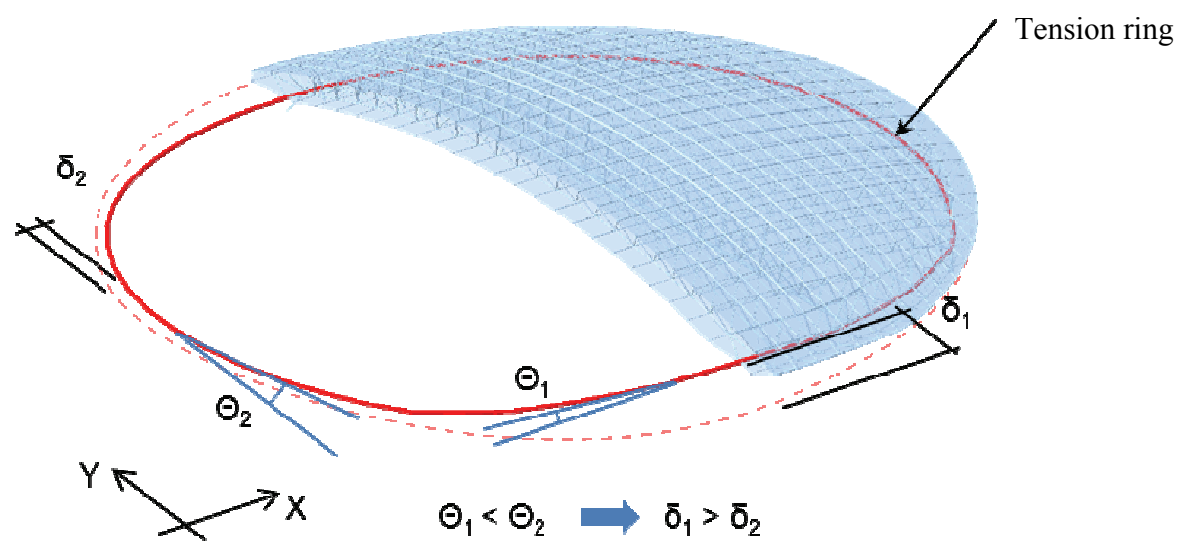

Fig. 7 Tension ring of the roof system.

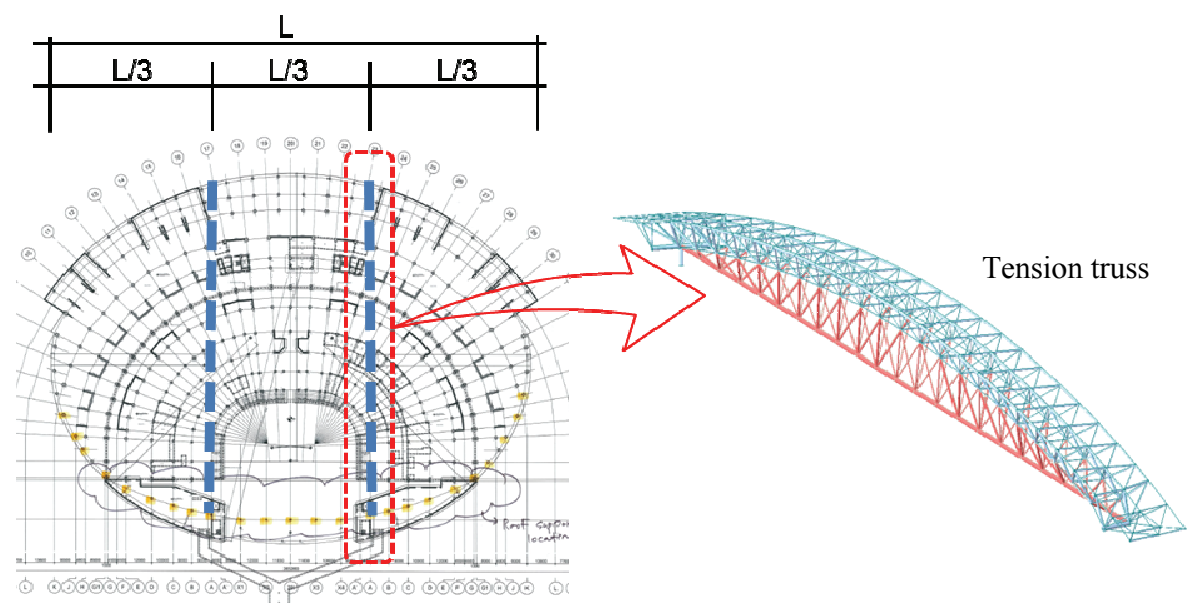

Fig. 8 Sub-tension truss. 


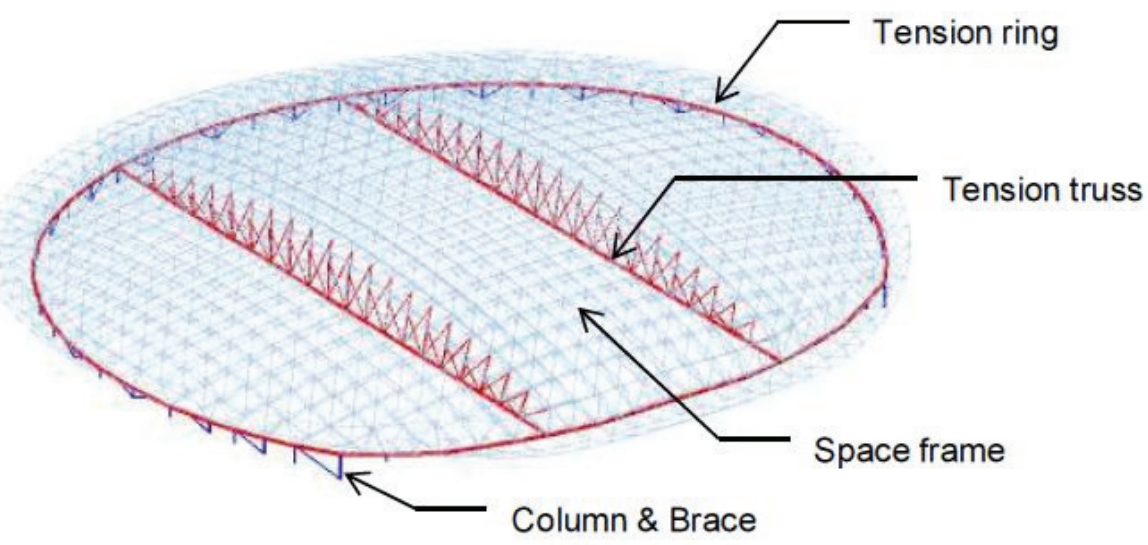

Fig. 9 Gravity load resistance system of roof.

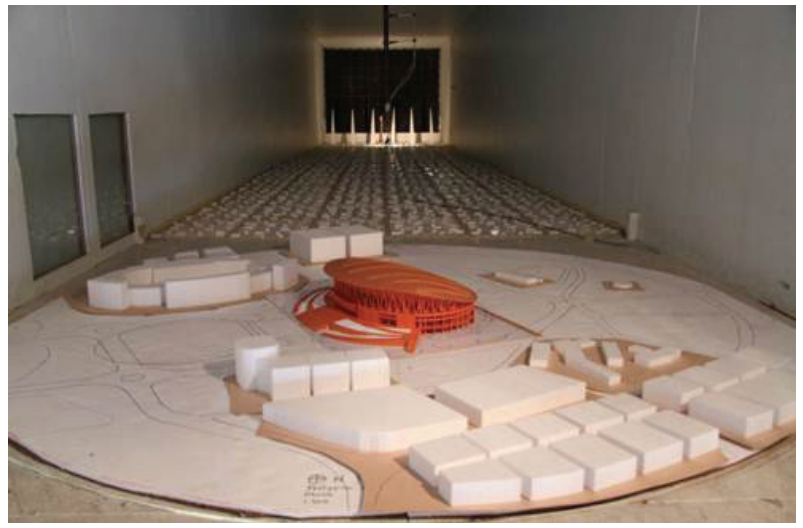

Fig. 10 Wind tunnel test.

Tension trusses help to restrain the movement of the roof edge, which increase the vertical stiffness of whole roof structure. The loads transferred to tension ring and tension trusses are carried down to the sub-structure through the supporting columns.

\subsubsection{Lateral Load Resistance System - Wind Load}

Wind loads on roof structure can be categorized into positive and negative pressure. As long as it is out of plane pressure, the behavior of wind load is similar to that of gravity load.

Philippine is in a region which experiences typhoon, so it is recommended that wind tunnel test (Fig. 10) should be performed to estimate design wind pressure. To evaluate more accurate wind pressure, wind tunnel test was conducted.

The dome had been divided into 42 tributary areas and panels. The net pressure on a panel was obtained by combining the external pressure coefficients acting on the tributary area by simultaneously differencing the external and back pressure acting on the area. The external pressure was determined based on the area weighting of the pressure sensors monitoring the pressures of the tributary area.

Wind tunnel test result showed that most part of the roof wind pressure is similar or little below than wind load from code except cantilevered roof area. This result was considered reasonable and applied to roof structure design. For the area that result of wind tunnel test was much smaller than code, the $80 \%$ of code value was applied.

4.2.3 Lateral Load Resistance System-Seismic Load

Seismic behavior of spatial structure was different from that of general structure. In spatial structure, even horizontal seismic load happens to cause vertical vibrations (Fig. 11). As vertical vibrations have a decisive effect on the whole structure, careful review was highly required by structural engineer.

For the reasons mentioned above, static and dynamic analysis (response spectrum analysis and linear time history analysis) were conducted for seismic load.

The earthquake wave of linear time history analysis was made by extracting the three artificial seismic loads, using response spectrum of MCE (maximum considered earthquake) level. These earthquakes should be scaled down to $2 / 3$ and applied to the structural DBE (design based earthquake) level. 


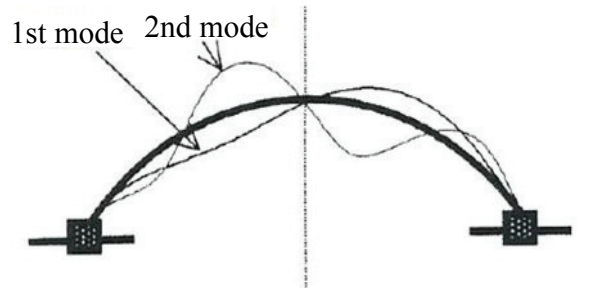

(a)

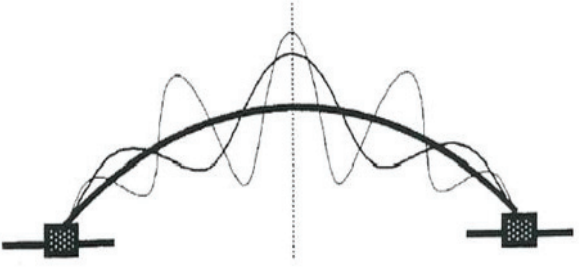

(b)

Fig. 11 Vibration of low rise dome structure: (a) horizontal vibration mode; (b) vertical vibration mode.

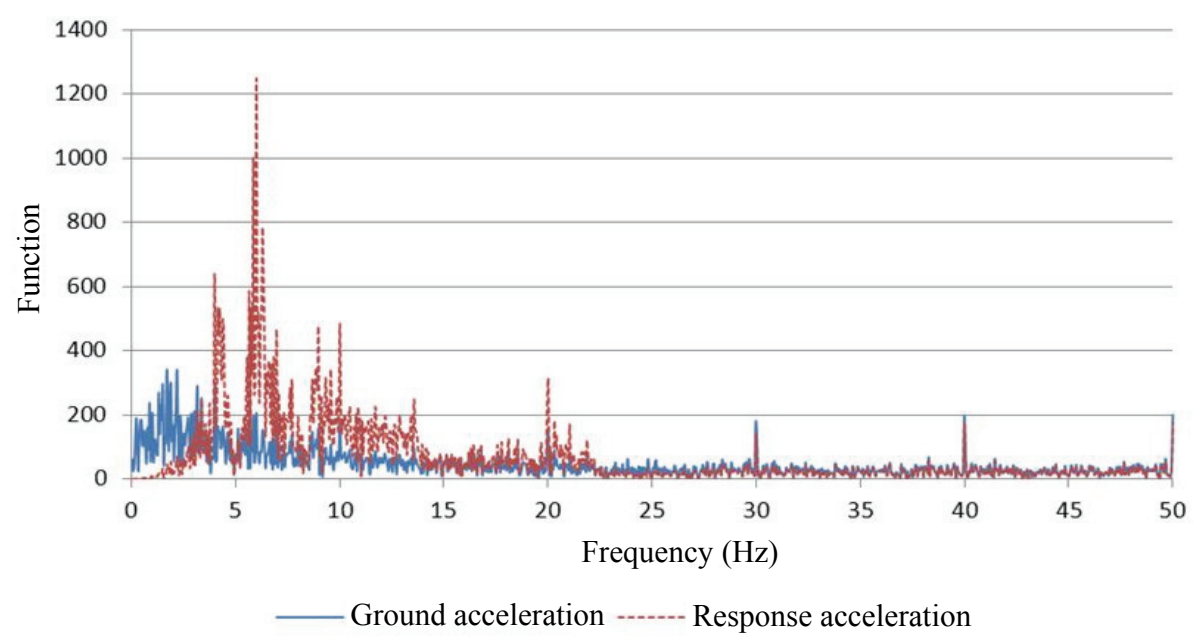

Fig. 12 Comparison of ground and response acceleration.

When ground acceleration passes the structures, response acceleration may be reduced or amplified according to dynamic characteristics of each structure. Hence, five points of the roof supports were selected from different sub-structure (three points from upper bowl, two points from service core). Then, response acceleration was compared with ground acceleration (Fig. 12). As Philippine Arena had short period, the response acceleration was greater than two to four times than ground acceleration itself.

For the reasons mentioned above, base isolation was applied for roof structure to minimize the amplification of seismic load from sub-structures. The detailed time history analysis procedure is explained in Section 4.5 of this paper.

\subsection{Roof Support System}

Number and location of columns had been modified from preliminary design to distribute load uniformly since space frame was selected. Separated roof support columns were combined and became to connect directly to inclined column of bowl. As a result, span of roof got larger, but the column axial force had been reduced and roof stiffness was increased since column bay got shorter (Fig. 13).

Current roof shape was drawn from torus, so span-rise ratio at the border area was small compared to center area of roof. By reducing supports of space at the border, it was able to generate balance of roof element. Various alternative studies to find the best solution are shown in Fig. 14.

For Alternative 1, elements size was larger because the span was further between the supports.

For Alternative 2, supports were added in the machinery room at back of stage to achieve economic design by reducing span size of roof. However, the supports in the end of span and middle occurred uplift and compression force due to different span distance ratio. 
- Preliminary design (truss system)
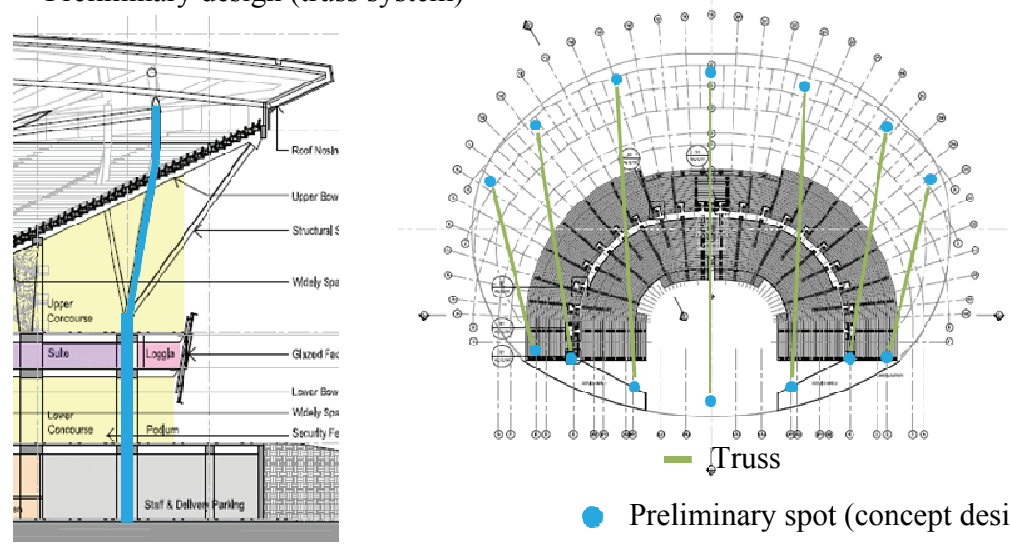

- Preliminary spot (concept design)

- Design shift (space frame system)
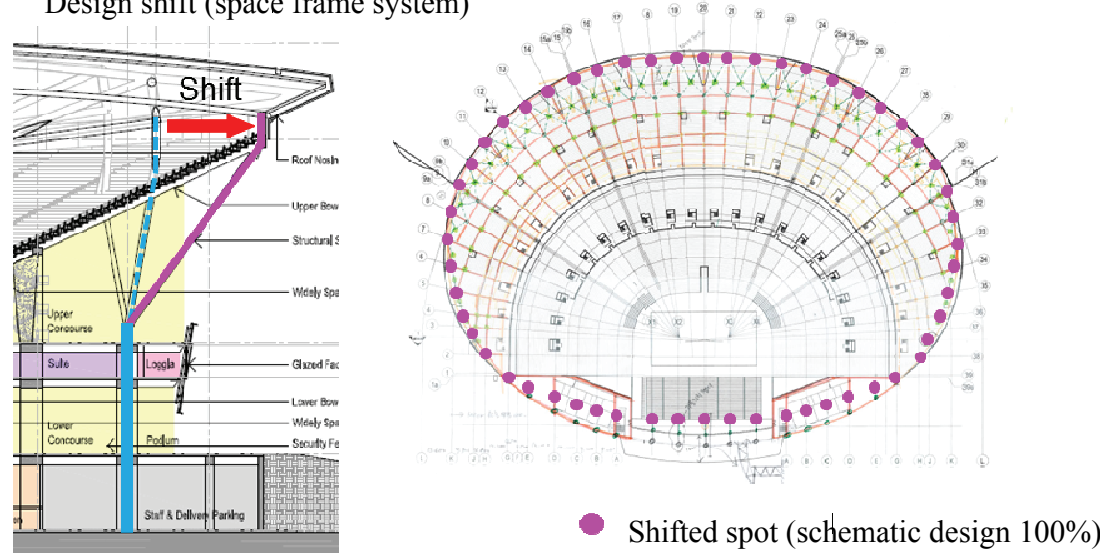

Fig. 13 Roof support modification (configuration).

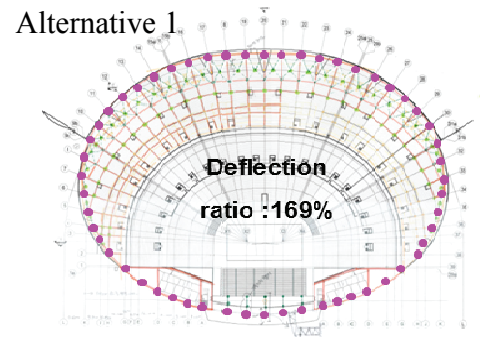

Alternative 2

Alternative 3
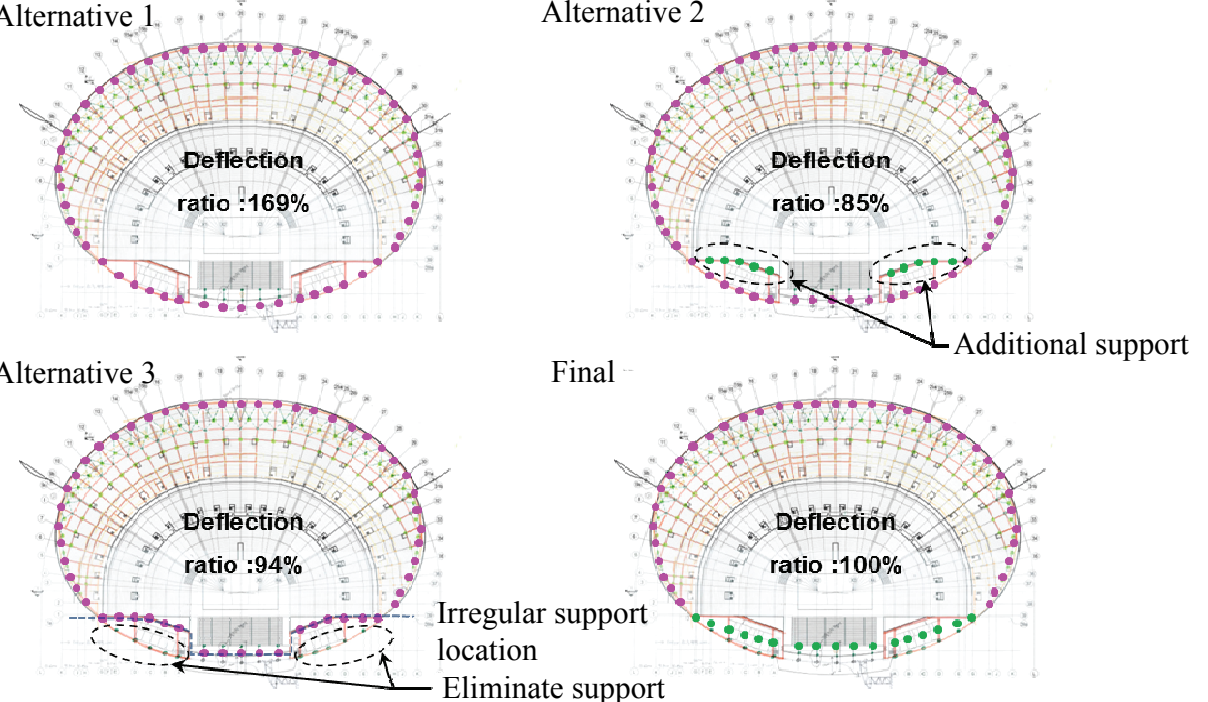

Fig. 14 Roof support study (location).

For Alternative 3, the solution of Alternative 2 changed to make cantilever at short span and eliminate the external support, but stress concentration occurred in certain area by a rapid change of support. 
Final solution was to prevent these problems discussed above, and maintained constant support around perimeter of the structure as moving support to machinery room that effect to span reduction by having same number of supports.

\subsection{Isolator}

The basic concept of base isolation is placing flexible element between upper and lower structure to reduce movement of upper structure. It can prevent seismic load to be delivered to upper structure and reduce overall damage of upper structure.

For Philippine Arena, LRB (lead rubber bearing) was applied as a base isolation system for its high energy dissipation ability. The lead core inside of the LRB provides the specific behavior which has different stiffness as external force reaches to designated value. From these characteristic of the LRB, displacement caused by normal use can be absorbed while lead core remains in elastic range. And against severe lateral loads like seismic load, it can provide high energy absorption capacity.

To confirm effectiveness of the LRB, response acceleration and member forces were compared between two cases, with and without LRB. When the isolators were installed, the response acceleration and member forces were reduced significantly as shown below (Fig. 15). Thus the structural design was progressed including stiffness of isolators.

\subsection{Non-linear Snapping Analysis}

For spatial structure with no columns inside, roof structure (Fig. 16) should resist external force with its shape.

While beam and column structure resist external forces by their bending and shear capacity, most spatial roof structure resist external force by axial and in-plane capacity of members, same for space frame system.

However, space frame system can have snap-through or bifurcation problem (geometric nonlinearity which can result in large deformation through the whole structure). Also, slender members in

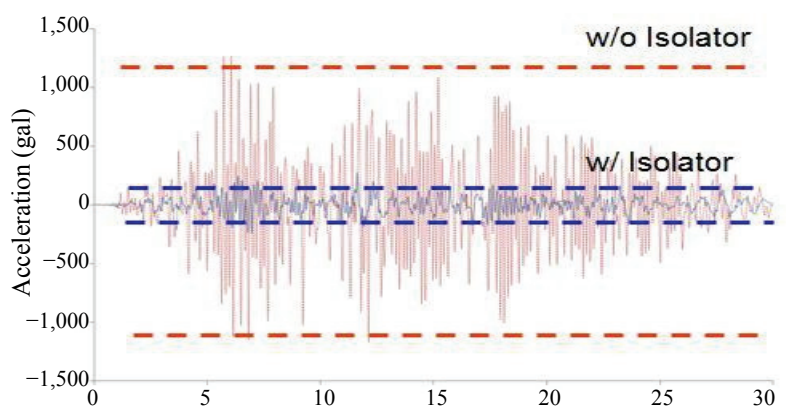

(a)

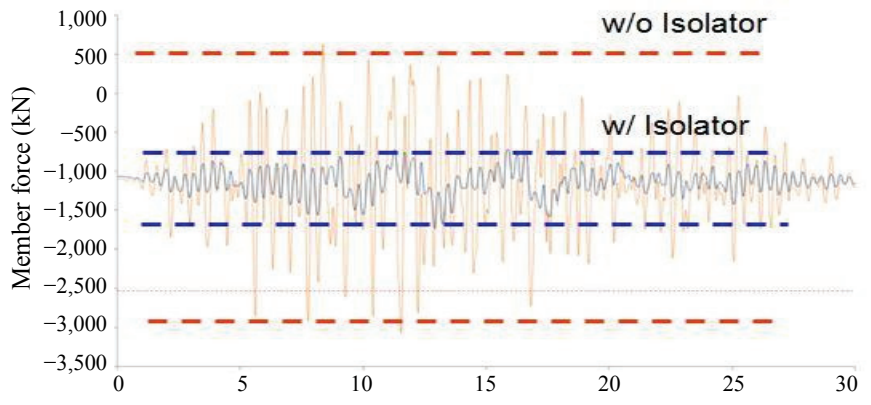

(b)

Fig. 15 Effect of LRB: (a) response acceleration; (b) member force-element No. 7930.

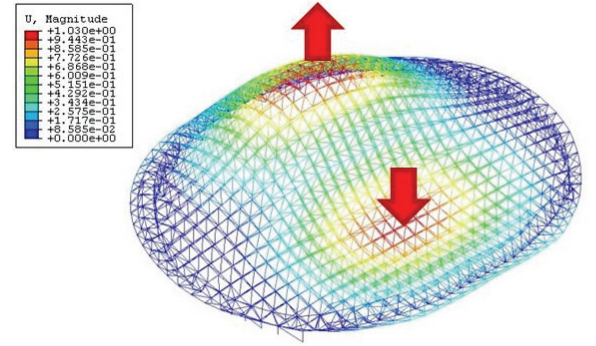

(a) 1 st mode

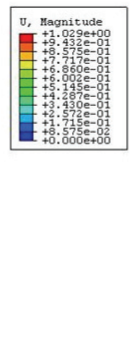

Fig. 16 Buckling mode shape of the roof.

(b) 2nd mode

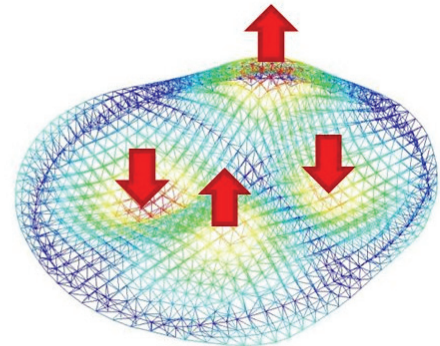




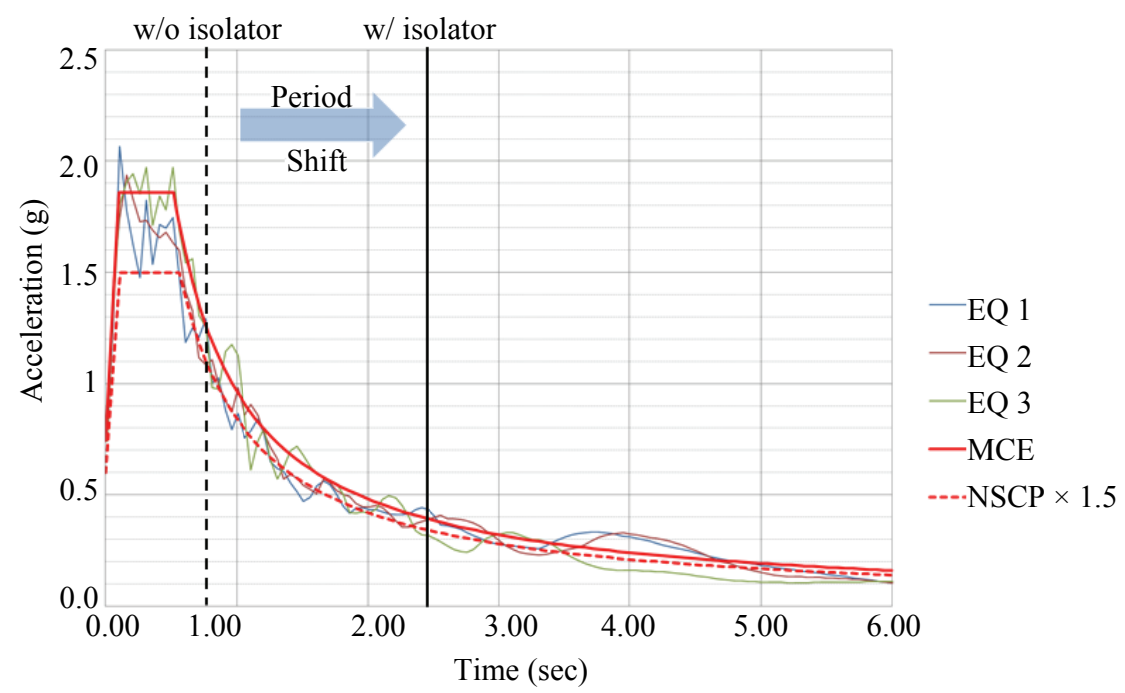

Fig. 17 Spectra of artificial earthquake ground motions.

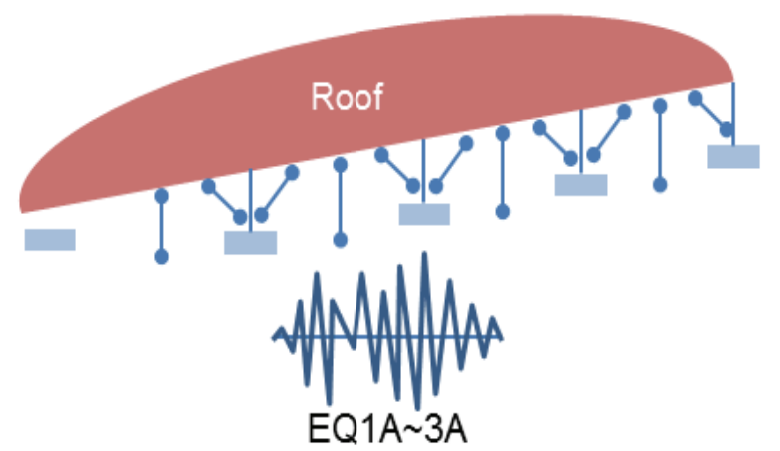

Fig. 18 Roof only model.

roof structure can reduce structural stability when local buckling is occurred (material nonlinearity).

Therefore, geometric and material nonlinear analysis [8] is highly recommended to secure the stability of spatial structure. Geometric and material nonlinear analysis of the Philippine Arena roof structure was performed using Abaqus.

\subsection{Time History Analysis}

In order to analyze the roof structure and isolators controlling seismic loads exactly, time history analysis [9-11] was performed. As mentioned in Section 4.2.3, The earthquake wave of linear-time history analysis was made by extracting the three artificial earthquake, using response spectrum of MCE level (Fig. 17). These earthquakes should be scaled down about $2 / 3$ and reflected to the structural design at
DBE level.

The structure can be divided into roof and sub-structure through the isolator. For convenience of analysis, sub-structure can be designed taking into account the reaction of the roof which is calculated by roof only model (Fig. 18). On the other hand, the roof can be analyzed by taking into account the translated load (or support acceleration) from sub-structure under the seismic load.

For reasons listed below, the analysis procedure using each models (roof and sub-structure) was expected to achieve approximate result:

(1) Roof only model cannot consider displacement of sub-structure which is caused by roof;

(2) Because same response of sub-structure was applied to roof only model due to nature of analysis method, roof only model could not reflect dynamic characteristic of sub-structure exactly.

So, the analysis using roof only model was performed on SD and DD stage for convenience of analysis. On CD stage, the earthquake analysis was performed by full model.

\subsubsection{Roof Only Model}

As mentioned above, on SD and DD stage, simplified roof only model was used for convenience of analysis. The precision of simplified method was subject to analysis conditions which was equivalent to original 
condition. To make this, it was important that the assumptions were minimized which could affect to analysis.

In case of roof only model, below conditions were considered:

(1) The deformation of sub-structure which supports roof is insignificant, so it does not affect the roof structure greatly;

(2) The ground acceleration (EQ 1 3) is amplified by the sub-structure. The amplified acceleration (EQ $1 \mathrm{~A} \sim 3 \mathrm{~A}$ ) is delivered to roof under seismic load;

(3) The acceleration delivered from sub-structure affects every support uniformly.

Based on the assumption, acceleration which is to applied on the roof only model is estimated. Five points which are expected to appear difference of stiffness are selected. Then, response acceleration was compared with ground acceleration at these points. The structure, having the performance of short period, showed results that response acceleration is greater than two to four times at these supports. For this reason, the isolation system was applied under the roof structures in order to minimize the amplification of seismic load from sub-structures.

\subsubsection{Full Model}

On CD stage, the full model analysis (Fig. 19) was performed to supplement inaccuracy of the roof only model analysis. Through full model analysis, the roof only model analysis was verified and actual seismic effect on the roof was reviewed. EQ 1 3 which is the original ground acceleration was applied on full model analysis.

The validity of the roof only model analysis was judged by comparing the amplified acceleration applied on roof structure with the response acceleration of roof supports from the full model analysis. The results are as follows:

As in Fig. 20, the maximum values of acceleration are similar. Even if there is some effectiveness due to this difference, it is expected not to affect on total structure largely.

Changes of dynamic characteristics were verified by comparing the eigenvalue analysis results of the full model and the roof only model (Table 1). The difference

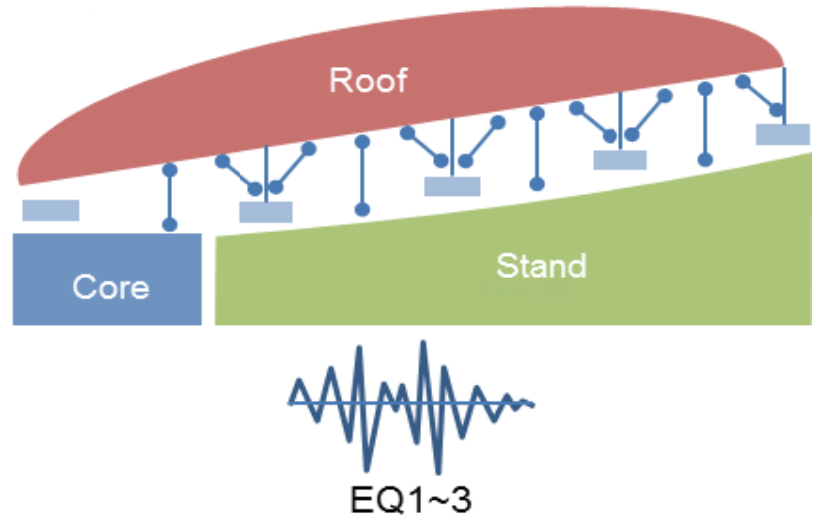

Fig. 19 Full model.

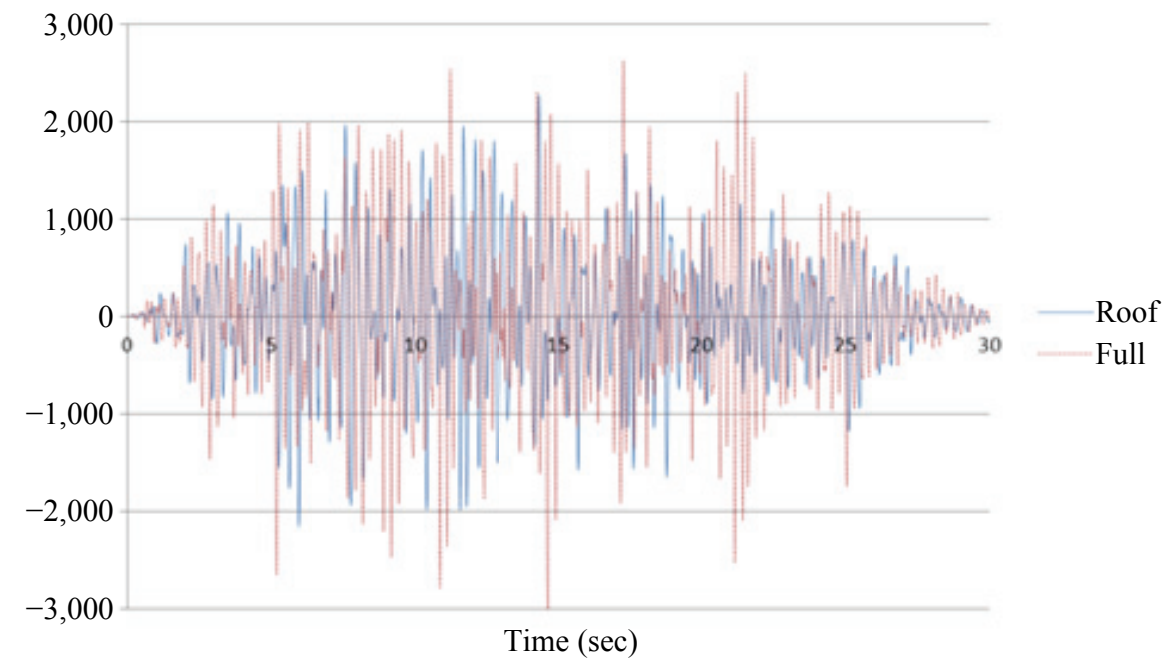

Fig. 20 Difference in acceleration between two models. 


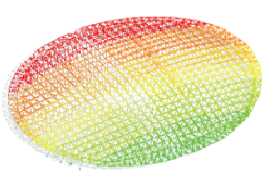

1 st mode

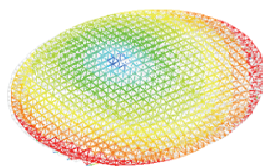

3rd mode

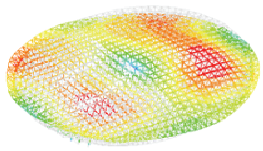

5th mode

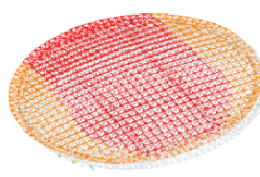

2nd mode

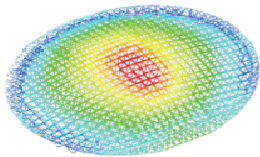

4th mode

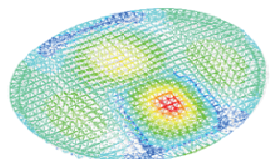

(a)

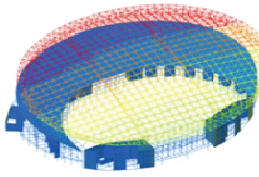

1 st mode

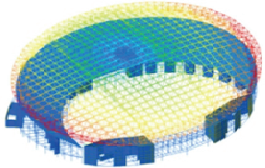

3rd mode

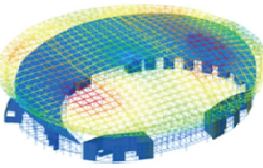

5th mode

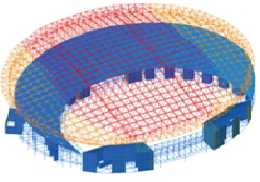

2nd mode

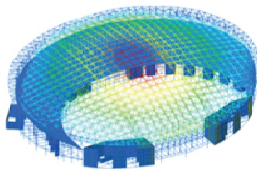

4th mode

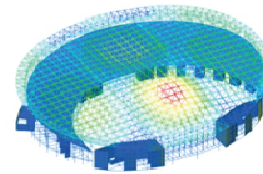

(b) 7th mode

Fig. 21 Mode shape of the two models: (a) roof only model; (b) full model.

Table 1 Eigenvalue comparison of the two model.

\begin{tabular}{llll}
\hline \multirow{2}{*}{ Mode } & \multicolumn{2}{c}{ Frequency $(\mathrm{Hz})$} & Difference \\
\cline { 2 - 4 } & Roof only model & Full model & 0 \\
\hline 1st mode: translation-X & 0.450 & 0.450 & +4 \\
2nd mode: translation-Y & 0.495 & 0.474 & +3 \\
3rd mode: rotation-Z & 0.689 & 0.667 & +6 \\
4th mode: translation-Z & 1.041 & 0.980 & +6 \\
5th mode: rotation-Y & 1.219 & 1.149 & +6 \\
7th mode: rotation-X & 1.515 & 1.428 & \\
\hline
\end{tabular}
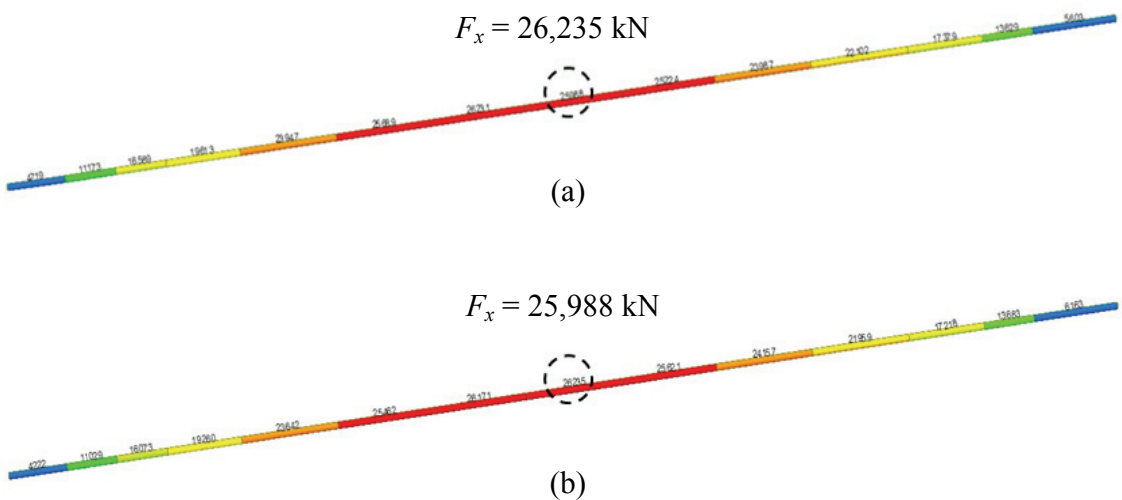

(b)

Fig. 22 Member force in lower chord comparison: (a) roof only model; (b) full model.

of eigenvalue between two models is under $6 \%$, and both of them represent same mode shapes (Fig. 21).

Also, in order to evaluate effect of seismic load on the roof structure, the lower chord member forces of tension truss where the largest stress occurs were compared (Fig. 22). The axial force of the roof only model analysis under EQ 1A 3A and the axial force of the full model analysis under EQ 1 3 were compared, and it shows same results.

As referred above, it is reviewed that validity of the roof only model on SD, DD stages by checking its response acceleration, eigenvalue and member forces. Consequently, the structural system review through simplified model is considered as appropriate method. 


\section{Conclusions}

The Philippine Arena consists of a roof structure, upper bowl, lower bowl and service core with loading dock. This paper introduces main design issues in structural design of the structure. It explained what system each part has and how it performs. Since the structure is the world's largest non-column arena in the world, structural design of the roof system was examined thoroughly from shape of supporting column to time history analysis. The Philippine Arena Project was a great chance to perform various studies for spatial structures.

\section{References}

[1] American Concrete Institute Committee. 2008. Building Code Requirements for Structural Concrete and Commentary (ACI318-08). Michigan: American Concrete Institute.

[2] Architectural Institute of Korea. 2007. Korean Structural Concrete Design Code 2007. Seoul: Architectural Institute of Korea.

[3] American Institute of Steel Construction Committee.
2003. Manual of Steel Construction: Load and Resistance Factor Design. Chicago: American Institute of Steel Construction.

[4] American Institute of Steel Construction Committee. 2010. Specification for Structural Steel Buildings. Chicago: American Institute of Steel Construction.

[5] Architectural Institute of Korea. 2007. Design of Spatial Structure. Seoul: Architectural Institute of Korea.

[6] Architectural Institute of Korea. 2006. Design Development of the Design and Constructional Technique for Large Space Structures. Seoul: Architectural Institute of Korea.

[7] Kōichirō, H. 1986. Shells, Membranes and Space Frames. Amsterdam: Elsevier.

[8] Seong, D. K. 2007. Research of Nonlinear Snapping of Speedom's Upper Structure. Technical report for CS Structural Engineering, Se-myung University, Jecheon.

[9] Association of Structural Engineers of the Philippines. 2010. National Structural Code of the Philippines 2010 (NSCP 2010). Manila: Association of Structural Engineers of the Philippines.

[10] International Code Council. 2009. International Building Code 2009 (IBC 2009). Birmingham: International Code Council.

[11] International Conference of Building Officials. 1997. Uniform Building Code 1997 (UBC 1997). Brea: International Conference of Building Officials. 